OPEN ACCESS

Edited by:

Wenquan Zou,

Case Western Reserve University,

United States

Reviewed by:

Philip Wade Tipton,

Mayo Clinic Florida, United States

Shan Ali,

Mayo Clinic Florida, United States

${ }^{*}$ Correspondence:

Patrycja Krzosek

patrycja.krzosek@op.pl

Specialty section:

This article was submitted to

Parkinson's Disease

and Aging-related Movement

Disorders,

a section of the journal

Frontiers in Aging Neuroscience

Received: 29 October 2021

Accepted: 10 January 2022

Published: 09 February 2022

Citation:

Krzosek P, Madetko N, Migda A, Migda B, Jaguś $D$ and Alster $P$ (2022)

Differential Diagnosis of Rare

Subtypes of Progressive

Supranuclear Palsy and PSP-Like

Syndromes-Infrequent

Manifestations of the Most Common

Form of Atypical Parkinsonism.

Front. Aging Neurosci. 14:804385.

doi: 10.3389/fnagi.2022.804385

\section{Differential Diagnosis of Rare Subtypes of Progressive Supranuclear Palsy and PSP-Like Syndromes - Infrequent Manifestations of the Most Common Form of Atypical Parkinsonism}

\author{
Patrycja Krzosek ${ }^{1 *}$, Natalia Madetko², Anna Migda ${ }^{3}$, Bartosz Migda ${ }^{4}$, Dominika Jaguś ${ }^{4}$ \\ and Piotr Alster ${ }^{2}$ \\ 'Students' Scientific Association of the Department of Neurology, Medical University of Warsaw, Warsaw, Poland, \\ ${ }^{2}$ Department of Neurology, Medical University of Warsaw, Warsaw, Poland, ${ }^{3}$ Department of Internal Medicine \\ and Endocrinology, Medical University of Warsaw, Warsaw, Poland, ${ }^{4}$ Diagnostic Ultrasound Lab, Department of Pediatric \\ Radiology, Medical Faculty, Medical University of Warsaw, Warsaw, Poland
}

Presently, there is increasing interest in rare PSP (progressive supranuclear palsy) variants, including PSP-PGF (PSP-progressive gait freezing), PSP-PI (PSP-postural instability), PSP-OM (PSP-ocular motor dysfunction), PSP-C (PSP-predominant cerebellar ataxia), PSP-CBS (PSP-corticobasal syndrome), PSP-SL (PSPspeech/language disorders), and PSP-PLS (PSP-primary lateral sclerosis). Diagnosis of these subtypes is usually based on clinical symptoms, thus thorough examination with anamnesis remains a major challenge for clinicians. The individual phenotypes often show great similarity to various neurodegenerative diseases and other genetic, autoimmune, or infectious disorders, manifesting as PSP-mimicking syndromes. At the current stage of knowledge, it is not possible to isolate a specific marker to make a definite ante-mortem diagnosis. The purpose of this review is to discuss recent developments in rare PSP phenotypes and PSP-like syndromes.

Keywords: progressive supranuclear palsy, subtypes, variants, PSP-like syndrome, differentiation

\section{INTRODUCTION}

Progressive supranuclear palsy (PSP) has been known for more than half a century, but most of the reports are on PSP-Richardson syndrome (PSP-RS) and PSP-P (PSP-Predominant Parkinsonism) (Steele et al., 1964; Williams et al., 2005a). Growing interest is now associated with less common PSP phenotypes, including PSP-PGF, PSP-PI, PSP-OM, PSP-C, PSP-F, PSP-CBS, PSP-SL, and PSP-PLS. Most of them are included in The Movement Disorders Society (MDS) criteria, introduced in 2017 (Höglinger et al., 2017). This results in a higher sensitivity in the diagnosis of PSP compared with the National Institute of Neurological Disorders and Stroke and the Society for PSP (NINDS-SPSP) criteria issued in 1996 (87.9\% for MDS criteria versus 45.5\% for NINDS-SPSP criteria) (Litvan et al., 1996; Ali et al., 2019). The pathology of PSP is a 4-repeat tauopathy, and its phenotypic diversity is 
related to the accumulation of tau protein in different brain areas (Rösler et al., 2019; Kovacs et al., 2020). On the other hand, many other diseases may clinically resemble PSP. Effective in vivo studies of rare PSP phenotypes and PSP-mimicking syndromes are not available. This paper presents an overview and differential diagnosis of these disorders.

\section{PROGRESSIVE SUPRANUCLEAR PALSY-SUBCORTICAL}

\section{Progressive Supranuclear Palsy-Progressive Gait Freezing}

The main symptom of PSP-PGF is a gradual increase in difficulty with gait initiation that is levodopa-resistant (Williams et al., 2007; Höglinger et al., 2017). Imaging studies show deterioration limited to the basal ganglia, including atrophy in volumetric magnetic resonance imaging (MRI) and increased tracer uptake in 18F-flortaucipir positron emission tomography (PET) (Schonhaut et al., 2017; Whitwell et al., 2020).

PSP-PGF most often causes difficulties in the differential diagnosis with PSP-RS, Parkinson's disease (PD), and vascular Parkinsonism. Analysis of the rate of progression of symptoms may be useful in distinguishing between the aforementioned diseases. Early supranuclear gaze palsy, particularly combined with advanced executive dysfunction, is usually associated with PSP-RS; whereas, in PSP-PGF, oculomotor dysfunction often appears later, even about 9 years after the onset of the first symptoms (Williams et al., 2007; Respondek et al., 2014; Hong et al., 2015; Lee et al., 2018; Jabbari et al., 2020). Freezing of gait (FoG) is an early symptom in PSP-PGF; whereas, in PD, it generally occurs in late stages, and it is susceptible to levodopa and coexists with slowness of movement, tremor, and rigidity (Factor, 2008; Owens et al., 2016; Höglinger et al., 2017). Pons to midbrain area ratio (P/M ratio) differs among PSP-PGF, PSP$\mathrm{RS}$, and $\mathrm{PD}$, with the highest ratio value for PSP-RS, the lowest for PD, and at an intermediate ratio for PSP-PGF (Nakahara et al., 2019). However, the precision of differentiation estimated at about $70 \%$ based on the $\mathrm{P} / \mathrm{M}$ ratio is insufficient (Nakahara et al., 2019). Pyramidal tract dysfunction, ischemic changes on imaging studies, and a history of stroke may lead the diagnosis to vascular Parkinsonism, because these features are generally not characteristic of PSP-PGF (Williams et al., 2007).

\section{Progressive Supranuclear Palsy-Postural Instability}

Progressive Supranuclear Palsy-Postural Instability (PSP-PI) is associated with predominant falls and balance problems (Kurz et al., 2016; Höglinger et al., 2017). Some studies present a correlation between the damage to the indirect locomotor pathway with its connections to the pedunculopontine nucleus and postural instability in PSP patients (Brown et al., 2020). Decreased 18F-FDG-PET metabolism is observed in the structures involved in this circuit compared to the group of healthy controls; however, increased metabolism is found within the precentral gyrus (Zwergal et al., 2011, 2013). Precuneus, sensorimotor gyrus, frontal cortex, and parietal cortex present an increased uptake of $18 \mathrm{~F}-\mathrm{THK} 5351$ in PSP patients with unjustified, repetitive falls within 3 years $[P 1$ feature according to the MDS criteria (Höglinger et al., 2017) compared to the patients without $P 1$ feature (Hsu et al., 2020)].

PSP-PI may cause difficulties in the differential diagnosis with PSP-RS. One study (Respondek et al., 2014) evaluated symptoms progression in PSP variants. Among the 18 patients with PSPPI, there was no oculomotor dysfunction during the first year of the disease. In a group of 24 patients with PSP-RS, this symptom was common, affecting approximately $40 \%$ of patients. Therefore, the appearance of supranuclear gaze palsy in the first year of the disease may argue against the PSP-PI, although the diagnosis should not be based solely on this one premise.

\section{Progressive Supranuclear Palsy-Ocular Motor Dysfunction}

Progressive Supranuclear Palsy-Ocular Motor Dysfunction (PSP$\mathrm{OM}$ ) is associated with predominant oculomotor dysfunction (Höglinger et al., 2017). There is no imaging data in PSP-OM, but one study presents a correlation between the degree of decreased fractional anisotropy (FA) index in the midbrain in MRI and the severity of abnormal vertical eye movements in PSP (Quattrone et al., 2019). In PSP patients with supranuclear gaze palsy [feature $\mathrm{O} 1$ according to the MDS criteria (Höglinger et al., 2017)], midbrain damage is greater compared to those with slow velocity of saccades [feature O2 according to the MDS criteria (Höglinger et al., 2017; Quattrone et al., 2019)]. It is also consistent with another PET study that shows an increased 18FTHK5351 uptake in midbrain, raphe nucleus, and red nucleus in PSP patients with ocular motor dysfunction compared with the group without oculomotor abnormalities (Hsu et al., 2020). The anterior cingulate cortex may also be involved in the pathogenesis of downward gaze palsy in PSP, since one study presents bilateral hypometabolism in the anterior cingulate cortex in 18-FDG-PET studies in these cases (Amtage et al., 2014).

The differential diagnosis mainly includes PSP-RS. In one study (Respondek et al., 2014), among 7 patients with PSPOM, no falls were documented within the first year of the disease. In a group of 24 patients with PSP-RS, this symptom was common, affecting approximately $80 \%$ of patients. Therefore, the appearance of falls in the first year of the disease may argue against PSP-OM. This can be a valuable clue, but should not be the single determining factor in the diagnosis.

\section{Progressive Supranuclear Palsy-Predominant Cerebellar Ataxia}

Progressive Supranuclear Palsy-Predominant Cerebellar Ataxia (PSP-C) appears to be a common subtype of PSP only in Asia, but the exact factors contributing to the disproportionate occurrence of this variant worldwide have not yet been determined (Kanazawa et al., 2009; Koga et al., 2016; Ando et al., 2020). Precise diagnostic criteria for PSP-C are not established due to its rarity (Höglinger et al., 2017). Falls are not a differentiating factor with other subtypes, but they occur in almost all patients with PSP-C (Ando et al., 2020). There is a case of one patient 
with advanced-stage PSP-C with widening of the pontocerebellar cistern in MRI (Kanazawa et al., 2012). To date, early-stage PSP$\mathrm{C}$ has been documented in PET studies using [18F]PM-PBB3 also in only one patient (Ishizuchi et al., 2021). Increased tracer uptake was found in the midbrain, subthalamic nucleus, and dentate nucleus (Ishizuchi et al., 2021).

PSP-C may cause difficulties in the differential diagnosis with multiple system atrophy-cerebellar type (MSA-C) and with genetic PSP-like syndromes (Stamelou et al., 2013; Koga et al., 2015). PSP-C is usually associated with later disease onset than MSA-C (approximately 68.8 years versus 58.3 years) and the lack of autonomic dysfunction (Kanazawa et al., 2013). Suspicion of genetic PSP-like syndrome with ataxia should be aroused primarily by a rapid and abrupt course and uncharacteristic neurological (stimulus-sensitive myoclonus, migraine, cataplexy, neuropathy, seizures) and nonneurological symptoms (splenomegaly, psychiatric symptoms, hearing loss) (Stamelou et al., 2013). Differential diagnosis should include familial Creutzfeld Jacob disease (CJD), mitochondrial diseases (including polymerase-gamma mutations), adult- onset Niemann Pick disease type C (NPC), and spinocerebellar ataxia type 2 and type 3 (Stamelou et al., 2013).

\section{PROGRESSIVE SUPRANUCLEAR PALSY-CORTICAL}

\section{Progressive Supranuclear Palsy-Corticobasal Syndrome}

Progressive Supranuclear Palsy-Corticobasal Syndrome (PSPCBS) is suggested by the overlapping of impaired limb motor function with apraxia, alien limb syndrome, and the disorder of cortical sensory function (Ling et al., 2014; Höglinger et al., 2017). Volumetric MRI can show asymmetric changes in the supplemental motor and premotor area of the cortex or prefrontal cortex in addition to atrophy of the basal nuclei, midbrain, and superior cerebellar peduncle (Whitwell et al., 2010, 2020). Asymmetric reduced 18F-FDG uptake in PET, compared to the group of healthy controls, was also found in the caudate nucleus, the anterior and middle area of cingulate gyrus, middle frontal gyrus and precentral gyrus (Pardini et al., 2019).

PSP-CBS may cause difficulties in the differential diagnosis with Alzheimer's disease (AD), frontotemporal lobar degeneration with TAR-DNA binding protein (FTLD-TDP), and corticobasal degeneration (CBD) (Whitwell et al., 2010; Coughlin and Litvan, 2020). Analysis of phosphorylated tau protein and amyloid- $\beta 1-42$ levels in cerebrospinal fluid (CSF) and an amyloid PET scan may be necessary to rule out $\mathrm{AD}$ as a major cause of CBS (Höglinger et al., 2017). Myoclonus is not a differentiating factor with other diseases, but it often occurs in patients with CBS-AD (Hu et al., 2009; Shelley et al., 2009; Hassan et al., 2011; Sakae et al., 2019). CBS-AD patients shows as an asymmetric decreased tracer uptake in 18F-FDG-PET and asymmetric atrophy in the MRI in the temporo-parietal areas as opposed to the changes in the PSP-CBS described above (Whitwell et al., 2010; Pardini et al., 2019). On the other hand, in CBS-TDP, atrophy is more pronounced in the prefrontal areas (Whitwell et al., 2010). Genetic testing can be used to rule out the presence of mutations suggestive of FTLD, regarding mainly GRN gene (Arienti et al., 2021). Differential diagnosis of PSP and CBD based on clinical presentation is extremely difficult, so PSP-CBS is generally classified as "probable 4R-tauopathy" (Ali and Josephs, 2017; Höglinger et al., 2017).

\section{Progressive Supranuclear Palsy-Frontal}

Progressive Supranuclear Palsy-Frontal (PSP-F) is generally associated with frontal lobe damage resulting in behavioural and cognitive impairment (Höglinger et al., 2017). In volumetric MRI, the prefrontal cortex is affected, along with the midbrain, basal ganglia, and superior cerebellar peduncle (Whitwell et al., 2020). One study shows a correlation between the deficit of executive functions in PSP and the reduced perfusion of the posterior area of the midcingulate cortex in technetium-99m-hexamethyl-propylenamine-oxime single photon emission computed tomography (99mTc-HMPAO SPECT) (Chiu et al., 2012). Patients included in the study (Chiu et al., 2012) were diagnosed as PSP-RS based on NINDS-SPSP criteria.

Alzheimer's disease (AD), psychiatric disorders, FTLD-TDP, and frontotemporal lobar degeneration with tau pathology (FTLD-tau) may cause problems in the differential diagnosis of PSP-F (Seeley, 2019; Coughlin and Litvan, 2020). Alzheimer's disease should be ruled out using CSF biomarkers or amyloid PET (as in the CBS-AD described above) (Seeley, 2019). Low level of neurofilament light chains (Nfl) in cerebrospinal fluid excludes neurodegeneration with a high likelihood; therefore, it may probably be useful in differentiating PSP-F with psychiatric disorders (Vijverberg et al., 2017; Katisko et al., 2019). Genetic causes of FTLD, including MAPT, PGRN and C9orf72 genes, should be excluded; C9orf72 is particularly often related to behavioural variant of frontotemporal dementia, with the presence of motor neuron disease symptoms, which are absent in PSP-F (Rademakers et al., 2012; Pan and Chen, 2013; Seeley, 2019). Cognitive problems in frontotemporal dementia with tau pathology was associated with low perfusion within the anterior midcingulate cortex in 99mTc-HMPAO SPECT in one study (Chiu et al., 2012), as opposed to the PSP changes described above (Vogt, 2016).

\section{Progressive Supranuclear Palsy-Speech/Language Disorders}

Even more than $50 \%$ of patients with isolated nonfluent/agrammatic primary progressive aphasia (nfPPA) or progressive apraxia of speech (AoS) develops other symptoms that could lead to a diagnosis of PSP-SL in subsequent years (Rohrer et al., 2010; Whitwell et al., 2019). Progression correlates with the advance of the patient's age, atrophy of the midbrain, and it is more common in patients with AoS (Whitwell et al., 2019). According to Botha and Josephs (2019), in AoS "the dorsolateral premotor cortex, motor cortex proper, and supplementary motor areas" can be affected, while nfPPA is often related to the anterior involvement of the Sylvian fissure regions and opercular 
regions of the dominant hemisphere. This is reflected in the volumetric MRI findings with the atrophy of the motor cortex and premotor cortex, and with brainstem structures involved to a lesser extent (Whitwell et al., 2020). PET studies using $18 \mathrm{~F}$-flortaucipir follow the same pattern with increased tracer uptake in cortical areas (Whitwell et al., 2020). Similarly, there is a case of one patient with PSP and non-fluent progressive aphasia with predominant increased 18F-THK5351 uptake in cortical frontal areas in PET studies (Brendel et al., 2018). NfPPA in PSP in 18F-FDG-PET studies can be correlated with decreased metabolism in the area of the left frontal lobe (including dorsolateral and medial areas) (Roh et al., 2010; Meyer et al., 2017).

PSP-SL causes difficulties in the differential diagnosis with FTLD-tau, FTLD-TDP, AD, and other PSP subtypes (Höglinger et al., 2017; Hofmann et al., 2019). FTLD-tau group account for the majority of all causes of nfPPA (Spinelli et al., 2017). Alzheimer's disease pathology should be excluded by amyloid PET and CSF biomarkers (as in the CBS-AD described above) (Perini et al., 2019). The fractional anisotropy (FA) index, which assesses the integrity of the white matter, is significantly lower in patients with PSP-SL compared to PSP-RS and PSP-P within the body of the corpus callosum (Lope-Piedrafita, 2018; Whitwell et al., 2021).

\section{Progressive Supranuclear Palsy-Primary Lateral Sclerosis}

Reports concerning PSP-PLS are non-specific, and this variant is not included in the MDS criteria (Höglinger et al., 2017). The presence of symptoms of upper motor neuron damage is a predominant element in the clinical presentation of this phenotype, while it is possible, but not necessary, to find features typical for PSP, including the most characteristic ones-falls and downward gaze palsy (Josephs et al., 2006; Nagao et al., 2012; King et al., 2013). Data on PSP-PLS imaging are limited. In neuropathological studies, an unusual distribution of tau accumulation is noted, with damage concerning mainly the motor cortex area, while relevant involvement of basal nuclei and brainstem is not a constant feature (Josephs et al., 2006; Nagao et al., 2012; King et al., 2013). Damage to the corticospinal tracts is also common (Josephs et al., 2006; Nagao et al., 2012; King et al., 2013).

With regard to the very limited reports on PSP-PLS, the diagnosis of this subtype is extremely difficult. Reduced FA in MRI-DTI in the superior cerebellar peduncle and corticospinal tracts can be a valuable diagnostic clue, as PLS patients with overlapping of PSP features can show damage not only to the corticospinal tract, but also to the superior cerebellar peduncle (Coon et al., 2012).

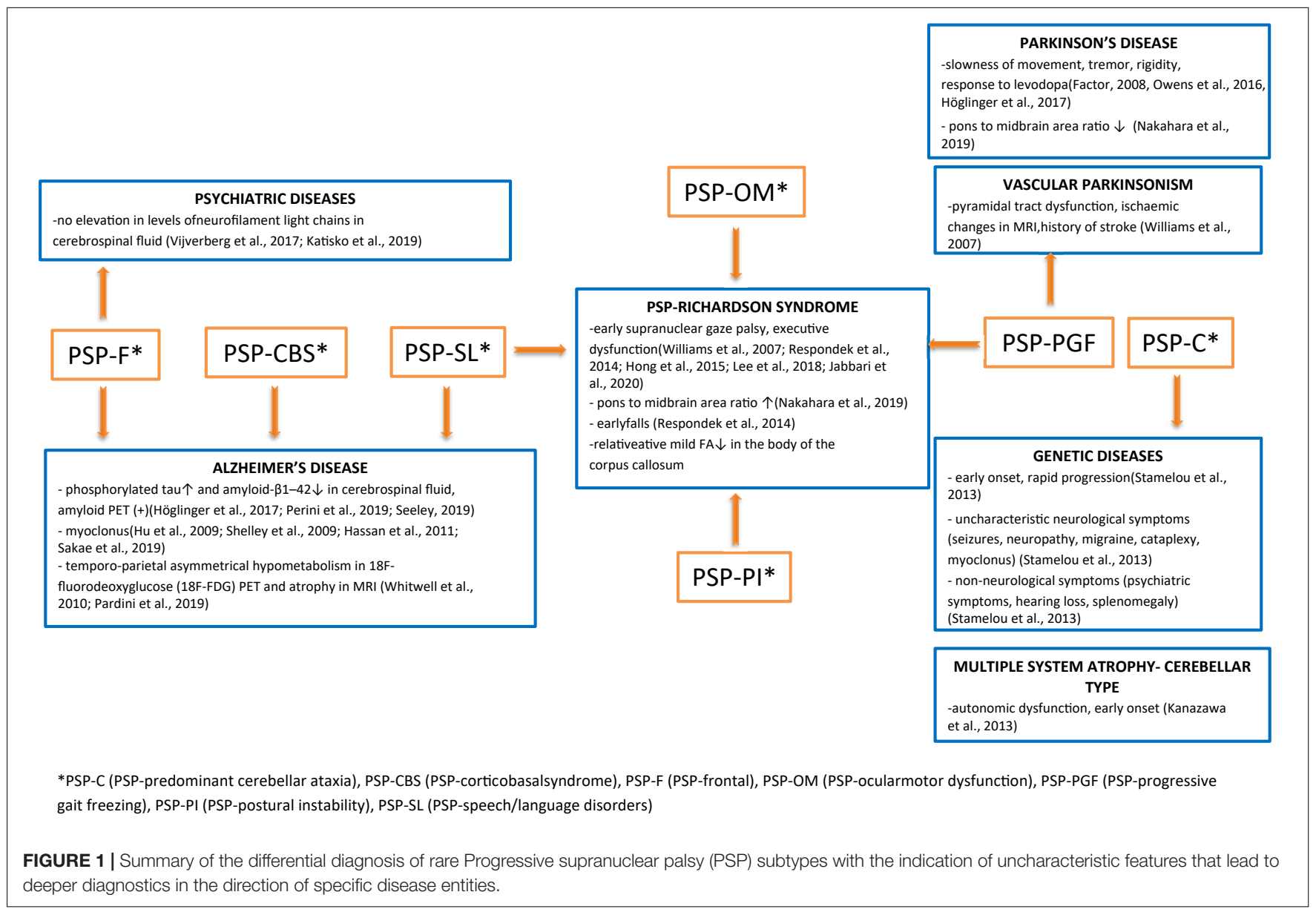


A summary of the differential diagnosis of rare variants of PSP is shown in Figure 1.

\section{PROGRESSIVE SUPRANUCLEAR PALSY-LIKE SYNDROMES}

\section{Genetic Progressive Supranuclear Palsy}

Progressive supranuclear palsy (PSP) can be associated with MAPT mutations (Im et al., 2015). Early onset of the disease, even before the age of 45, suggest a MAPT mutation, as sporadic PSP usually develops the first symptoms at the age of 63-65 (Golbe, 2014; Levin et al., 2016; Wen et al., 2021). The presence of neurodegenerative diseases in family history further increases the likelihood of genetic PSP (Wen et al., 2021). The association of LRRK2 mutations with PSP is still uncertain due to inconsistent study results, but according to some authors, it is considered an extremely rare cause of PSP (Im et al., 2015; Sanchez-Contreras et al., 2017; Wen et al., 2021).

Various genetic diseases can mimic PSP in their clinical picture, and these are called PSP-like syndromes (Stamelou et al., 2013; Wen et al., 2021). Most of these are adverted in other subsections (genetic forms of FTLD, familial CJD, adultonset NPC, mitochondrial diseases, spinocerebellar ataxia type 2 and type 3), but Perry syndrome and Kukor-Rakeb disease are also worth mentioning (Stamelou et al., 2013). Perry syndrome associated with a DNCT1 mutation can be related to a younger age of onset (approximately 56 years of age) and often with respiratory depression that are not typically found in the sporadic PSP (Stamelou et al., 2013; Höglinger et al., 2017; Barreto et al., 2021; Wen et al., 2021). On the other hand, Kufor-Rakeb syndrome (ATP13A2 mutations) is unique, both for its unusually early onset in young adults and for its response to levodopa treatment (Williams et al., 2005b; Stamelou et al., 2013; Im et al., 2015).

\section{PARANEOPLASTIC AND AUTOIMMUNE PROGRESSIVE SUPRANUCLEAR PALSY}

Progressive supranuclear palsy-like phenotype is potentially related to paraneoplastic syndromes, due to its demonstrated association with anti-Ma1 and anti-Ma2, anti-Hu, anti-CRMP5, and anti-Ri onconeuronal antibodies (Adams et al., 2011; Dash et al., 2016; Ohyagi et al., 2017; Takkar et al., 2020). The latter appear to be frequently correlated with breast cancer (Simard et al., 2020; Takkar et al., 2020). Other neoplasms associated with the syndrome include B-cell lymphoma, small cell lung carcinoma, and tonsil carcinoma (Tan et al., 2005; Adams et al., 2011; Dash et al., 2016).

Progressive supranuclear palsy-like syndrome may be also related to an autoimmune process (Balint et al., 2018). The dynamics of the development of symptoms in autoimmune PSP is different than in neuropathological PSP with the coexistence of atypical features (Table 1) (Hierro et al., 2020; González-Ávila et al., 2021). The association of anti-LGI1, anti-IgLON5, and anti-DPPX antibodies has been demonstrated (Tobin et al., 2014;
Gaig et al., 2017; Hierro et al., 2020), but many neuronal antibodies responsible for described phenotype have not yet been characterised (Kannoth et al., 2016). Of particular interest are cases of anti-IgLON5 disease with PSP- like presentation. In both anti-IgLON5 disease and PSP, abnormal vertical eye movements are found; however, upward gaze palsy can predominate in anti-IgLON5 disease, and mainly downward gaze abnormalities are observed in PSP (González-Ávila et al., 2021). The disease can last longer than sporadic PSP, and atypical symptoms may occur (Table 1) (Golbe, 2014; Levin et al., 2016; Gaig et al., 2017). On the other hand, the presence anti-LGI-1 antibodies may be associated with rapid development of symptoms (within months) and clinical improvement following the introduction of immunotherapy (Kannoth et al., 2016; Hierro et al., 2020).

\section{VASCULAR PROGRESSIVE SUPRANUCLEAR PALSY}

Vascular PSP is a rare syndrome associated with multiple ischemic lesions in various brain regions, including the brainstem, the basal ganglia, thalamus, frontal lobe, and cerebellum, without tau deposits characteristic of neurodegenerative PSP (Josephs et al., 2002). Clinical signs usually include falls, dementia, and other symptoms that mimic tau-related PSP, but a thorough physical examination additionally reveals atypical features (shown in Table 1) (Winikates and Jankovic, 1994; Josephs et al., 2002; Lanza et al., 2014). The key element of medical evaluation among this group of patients seems to be the assessment of cardiovascular risk factors and the demonstration of ischemic changes on imaging studies (Winikates and Jankovic, 1994; Josephs et al., 2002; Lanza et al., 2014).

\section{PROGRESSIVE SUPRANUCLEAR PALSY ASSOCIATED WITH INFECTIOUS AND PARASITIC DISEASES}

Progressive supranuclear palsy-like syndrome is a rare presentation of bacterial diseases, including Whipple disease and neurosyphilis, both with potential response to antibiotics (Murialdo et al., 2000; Magherini et al., 2007). Neurological manifestations in Whipple's disease usually do not appear until the advanced stages of the disease; however, in some cases, neurological disorders are the first and only symptoms of the disease (Gerard et al., 2002; Magherini et al., 2007). In contrast to neurodegenerative PSP, neurological examination reveals the lack of square wave jerks, more impaired upward than downward saccades, and oculomasticatory myrhythmia in some cases (Averbuch-Heller et al., 1999; Magherini et al., 2007). Imaging studies can show varied changes, but without midbrain atrophy characteristic of tau-related PSP (Panegyres et al., 2006; Peregrin and Malikova, 2015). In neurosyphilis, the presence of pupillary dysfunction is an important feature that may help in the differential diagnosis with tau-related PSP (Murialdo et al., 2000). Single cases of PSP-like syndrome in the course of viral 
TABLE 1 | Comparison of paraneoplastic, autoimmune and vascular Progressive supranuclear palsy (PSP) with neurodegenerative PSP.

\begin{tabular}{|c|c|c|c|c|c|}
\hline & Neurodegenerative PSP & $\begin{array}{l}\text { Paraneoplastic } \\
\text { PSP }\end{array}$ & Autoimmune PSP & Vascular PSP & Infectious PSP \\
\hline Disease course & $\begin{array}{l}\text { Insidious onset and slow } \\
\text { progression (years) (Golbe, } \\
\text { 2014; Levin et al., 2016; } \\
\text { Höglinger et al., 2017) }\end{array}$ & $\begin{array}{l}\text { Rapid progression (months) } \\
\text { (Tan et al., 2005; Adams } \\
\text { et al., 2011; Dash et al., } \\
\text { 2016; Takkar et al., 2020) }\end{array}$ & $\begin{array}{l}\text { Rapid progression } \\
\text { (months) or long } \\
\text { disease duration } \\
\text { (up to } 18 \text { years) } \\
\text { (Gaig et al., 2017; } \\
\text { Hierro et al., 2020) }\end{array}$ & $\begin{array}{l}\text { Sudden onset and rapid, } \\
\text { gradual progression } \\
\text { (Josephs et al., 2002; } \\
\text { Lanza et al., 2014) }\end{array}$ & $\begin{array}{l}\text { Rapid progression (Magherini } \\
\text { et al., 2007) }\end{array}$ \\
\hline Cerebrospinal fluid & $\begin{array}{l}\text { No established markers } \\
\text { (Höglinger et al., 2017) }\end{array}$ & $\begin{array}{l}\text { Possible: } \\
\text {-elevated protein (Tan et al., } \\
\text { 2005; Adams et al., 2011; } \\
\text { Ohyagi et al., 2017) } \\
\text {-elevated lgG (Adams et al., } \\
\text { 2011) } \\
\text {-pleocytosis (lymphocyte } \uparrow \text { ) } \\
\text { (Tan et al., 2005; Dash } \\
\text { et al., 2016) } \\
\text {-onconeuronal antibodies } \\
\text { (Dash et al., 2016; Simard } \\
\text { et al., 2020) }\end{array}$ & $\begin{array}{l}\text { Possible: } \\
\text {-normal or } \\
\text { inflammatory } \\
\text { (Hierro et al., 2020; } \\
\text { González-Ávila } \\
\text { et al., 2021) }\end{array}$ & Limited data & $\begin{array}{l}\text {-Polymerase chain reaction (+) } \\
\text { for Tropheryma whipplei } \\
\text { (Höglinger et al., 2017) } \\
\text { - elevated lgG, (+) VDRL test } \\
\text { (Veneral Diseases Research } \\
\text { Laboratory) (Murialdo et al., } \\
\text { 2000) }\end{array}$ \\
\hline MRI & $\begin{array}{l}\text { Midbrain atrophy (Höglinger } \\
\text { et al., 2017) }\end{array}$ & $\begin{array}{l}\text { Normal or uncharacteristic } \\
\text { changes without midbrain } \\
\text { atrophy (Tan et al., 2005; } \\
\text { Adams et al., 2011; Dash } \\
\text { et al., 2016; Ohyagi et al., } \\
\text { 2017) }\end{array}$ & Limited data & $\begin{array}{l}\text { Ischaemic changes in white } \\
\text { matter and in basal ganglia } \\
\text { (Josephs et al., 2002; } \\
\text { Lanza et al., 2014) }\end{array}$ & $\begin{array}{l}\text { Group of enhancing } \\
\text { lesions/single mass, without } \\
\text { midbrain atrophy (Panegyres } \\
\text { et al., 2006; Peregrin and } \\
\text { Malikova, 2015) }\end{array}$ \\
\hline $\begin{array}{l}\text { Additional } \\
\text { symptoms } \\
\text { associated with } \\
\text { neoplastic disease }\end{array}$ & Limited data & $\begin{array}{l}\text { Possible: } \\
\text {-haemoglobin } \downarrow \text {, cachaexia, } \\
\text { fever (Tan et al., 2005) } \\
\text {-history of neoplastic } \\
\text { disease (Takkar et al., 2020) } \\
\text {-paraneoplastic } \\
\text { neurological symptoms, } \\
\text { e.g., polyneuropathy (Tan } \\
\text { et al., 2005) }\end{array}$ & Limited data & Limited data & Limited data \\
\hline $\begin{array}{l}\text { Risk factors of } \\
\text { cerebrovascular } \\
\text { disease }\end{array}$ & $\begin{array}{l}\text { Hypertension (Rabadia } \\
\text { et al., 2019) }\end{array}$ & Limited data & Limited data & $\begin{array}{l}\text { Present (hypertension, } \\
\text { diabetes, smoking, prior } \\
\text { stroke, stenosis of carotid } \\
\text { arteries) (Winikates and } \\
\text { Jankovic, 1994; Lanza } \\
\text { et al., 2014) }\end{array}$ & Limited data \\
\hline $\begin{array}{l}\text { Non-characteristic } \\
\text { features in the } \\
\text { clinical picture }\end{array}$ & Not applicable & $\begin{array}{l}\text { Possible, e.g., } \\
\text {-horizontal gaze palsy and } \\
\text { anterocollitis (Takkar et al., } \\
\text { 2020) }\end{array}$ & $\begin{array}{l}\text { Possible, e.g., } \\
\text {-response to } \\
\text { immunotherapy } \\
\text { (Hierro et al., 2020) } \\
\text {-sleep disorders, } \\
\text { facial dyskinesia } \\
\text { (González-Ávila } \\
\text { et al., 2021) }\end{array}$ & $\begin{array}{l}\text { Possible, e.g., -pathologic } \\
\text { reflexes, unilateral paresis, } \\
\text { facial nerve palsy (Josephs } \\
\text { et al., 2002) } \\
\text {-loss of bladder control, } \\
\text { asymmetric symptoms } \\
\text { involving mainly the lower } \\
\text { body (Winikates and } \\
\text { Jankovic, 1994) }\end{array}$ & $\begin{array}{l}\text { Possible, e.g., } \\
\text {-response to antibiotics, } \\
\text { pupillary dysfunction (Murialdo } \\
\text { et al., 2000) } \\
\text {-gastrointestinal symptoms, } \\
\text { lymphadenopathy, } \\
\text { weight loss, oculomasticatory } \\
\text { myrhythmia (Magherini et al., } \\
\text { 2007) } \\
\text {-lack of square wave jerks, } \\
\text { more impaired upward than } \\
\text { downward saccades } \\
\text { (Averbuch-Heller et al., 1999) }\end{array}$ \\
\hline
\end{tabular}

infections (HIV virus) (Jang et al., 2011) and parasitic diseases (neurocysticercosis) (Sharma et al., 2011) are also described in the literature, but data about them are very limited.

The differential features of paraneoplastic, autoimmune, vascular, infectious, and neurodegenerative PSP are given in the Table 1.

\section{CONCLUSION}

This work highlights the clinical diversity of PSP subtypes. The lack of optimal tools to make a precise ante-mortem diagnosis of rare PSP variants, especially in the early stages, still remains a major difficulty for clinicians. The development of neuroimaging 
methods, mainly nuclear imaging techniques, gives clinicians a chance to change the standards of patient management. To date, most reports have been related to differences in 18FDG, 18F-flortaucipir and 18F-THK5351 uptake in PET across PSP variants, but new radiotracers are also emerging, such as [18F]PM-PBB3 (Amtage et al., 2014; Brendel et al., 2018; Pardini et al., 2019; Hsu et al., 2020; Whitwell et al., 2020; Ishizuchi et al., 2021). Determination of specific uptake patterns of individual markers is likely to make a breakthrough in the diagnostics of rare variants of PSP in cases where this is difficult or impossible on the basis of clinical features. The problem concerning the exclusion of PSP-like syndromes seems to be particularly important due to the overlapping of symptoms, the lack of consistent criteria, and biomarkers. Precise diagnosis could potentially be used to include patients in clinical trials for new PSP therapies (Boxer et al., 2017), and it is also important from the point of view of implementing treatment for reversible causes of PSP syndromes,

\section{REFERENCES}

Adams, C., McKeon, A., Silber, M. H., and Kumar, R. (2011). Narcolepsy, REM sleep behavior disorder, and supranuclear gaze palsy associated with Mal and Ma2 antibodies and tonsillar carcinoma. Arch. Neurol. 68, 521-524. doi: 10. 1001/ARCHNEUROL.2011.56

Ali, F., and Josephs, K. A. (2017). Corticobasal degeneration: key emerging issues. J. Neurol. 265, 439-445. doi: 10.1007/S00415-017-8644-3

Ali, F., Martin, P. R., Botha, H., Ahlskog, J. E., Bower, J. H., Masumoto, J. Y., et al. (2019). Sensitivity and specificity of diagnostic criteria for progressive supranuclear palsy. Mov. Disord. 34, 1144-1153. doi: 10.1002/mds.27619

Amtage, F., Maurer, C., Hellwig, S., Tüscher, O., Kreft, A., Weiller, C., et al. (2014). Functional correlates of vertical gaze palsy and other ocular motor deficits in PSP: an FDG-PET study. Parkinsonism Relat. Disord. 20, 898-906. doi: 10.1016/J.PARKRELDIS.2014.05.013

Ando, S., Kanazawa, M., and Onodera, O. (2020). Progressive supranuclear palsy with predominant cerebellar ataxia. J. Mov. Disord. 13, 20-26. doi: 10.14802/ jmd.19061

Arienti, F., Lazzeri, G., Vizziello, M., Monfrini, E., Bresolin, N., Saetti, M. C., et al. (2021). Unravelling genetic factors underlying corticobasal syndrome: a systematic review. Cells 10:171. doi: 10.3390/CELLS10010171

Averbuch-Heller, L., Paulson, G., Daroff, R., and Leigh, R. (1999). Whipple's disease mimicking progressive supranuclear palsy: thediagnostic value of eye movement recording. J. Neurol. Neurosurg. Psychiatry 66, 532-535. doi: 10. 1136/JNNP.66.4.532

Balint, B., Vincent, A., Meinck, H.-M., Irani, S. R., and Bhatia, K. P. (2018). Movement disorders with neuronal antibodies: syndromic approach, genetic parallels and pathophysiology. Brain 141, 13-36. doi: 10.1093/BRAIN/ AWX189

Barreto, R. D., Rodrigues, R., Roriz, J. M., Alonso, I., and Magalhães, M. (2021). Perry syndrome with progressive supranuclear palsy-like phenotype in a Portuguese family - long-term clinical follow-up. Parkinsonism Relat. Disord. 84, 74-76. doi: 10.1016/J.PARKRELDIS.2021.02.004

Botha, H., and Josephs, K. A. (2019). Primary progressive aphasias and apraxia of speech. Contin. Lifelong Learn. Neurol. 25, 101-127. doi: 10.1212/CON. 0000000000000699

Boxer, A. L., Yu, J.-T., Golbe, L. I., Litvan, I., Lang, A. E., and Höglinger, G. U. (2017). New diagnostics and therapeutics for progressive supranuclear palsy. Lancet Neurol. 16, 552-563. doi: 10.1016/S1474-4422(17)30157-6

Brendel, M., Schönecker, S., Höglinger, G., Lindner, S., Havla, J., Blautzik, J., et al. (2018). [18F]-THK5351 PET correlates with topology and symptom severity in progressive supranuclear palsy. Front. Aging Neurosci. 9:440. doi: 10.3389/fnagi. 2017.00440

Brown, F. S., Rowe, J. B., Passamonti, L., and Rittman, T. (2020). Falls in progressive supranuclear palsy. Mov. Disord. Clin. Pract. 7, 16-24. doi: 10.1002/mdc3. 12879 since it offers a chance to improve the prognosis and even to reduce the neurological deficit in some cases. Further research is needed to find suitable in vivo "biomarkers" for the different variants of the disease. Nevertheless, this work allows clinicians to accurately target the medical examination and the anamnesis, which currently still remain the basis for the diagnosis of the rare variants of this atypical Parkinsonism.

\section{AUTHOR CONTRIBUTIONS}

PK involved in the study design, data analysis, review of the literature, writing - original draft preparation, and writing - review and editing. NM, AM, BM, and DJ involved in the review and editing. PA involved in the study design, writing review and editing, supervision, and final acceptance. All authors contributed to the article and approved the submitted version.

Chiu, W. Z., Papma, J. M., de Koning, I., Kaat, L. D., Seelaar, H., Reijs, A. E. M., et al. (2012). Midcingulate involvement in progressive supranuclear palsy and tau positive frontotemporal dementia. J. Neurol. Neurosurg. Psychiatry 83, 910-915. doi: 10.1136/JNNP-2011-302035

Coon, E. A., Whitwell, J. L., Jack, C. R., and Josephs, K. A. (2012). Primary lateral sclerosis as progressive supranuclear palsy: diagnosis by diffusion tensor imaging. Mov. Disord. 27, 903-906. doi: 10.1002/mds.24990

Coughlin, D. G., and Litvan, I. (2020). Progressive supranuclear palsy: advances in diagnosis and management. Parkinsonism Relat. Disord. 73, 105-116. doi: 10.1016/J.PARKRELDIS.2020.04.014

Dash, D., Choudhary, R., Ramanujam, B., Vasantha, P. M., and Tripathi, M. (2016). Paraneoplastic syndrome mimicking progressive supranuclear palsy. J. Clin. Neurosci. 32, 162-163. doi: 10.1016/J.JOCN.2016.02.032

Factor, S. A. (2008). The clinical spectrum of freezing of gait in atypical Parkinsonism. Mov. Disord. 23, S431-S438. doi: 10.1002/mds.21849

Gaig, C., Graus, F., Compta, Y., Högl, B., Bataller, L., Brüggemann, N., et al. (2017). Clinical manifestations of the anti-IgLON5 disease. Neurology 88, 1736-1743. doi: 10.1212/WNL.0000000000003887

Gerard, A., Sarrot-Reynauld, F., Liozon, E., Cathebras, P., Besson, G., Robin, C., et al. (2002). Neurologic presentation of Whipple disease: report of 12 cases and review of the literature. Medicine 81, 443-457. doi: 10.1097/00005792200211000-00005

Golbe, L. I. (2014). Progressive supranuclear palsy. Semin. Neurol. 34, 151-159. doi: $10.1055 / \mathrm{s}-0034-1381736$

González-Ávila, C., Casado, L., García, I. M., Villacieros-Álvarez, J., Vivancos, J., and Quintas, S. (2021). Altered ioflupane single-photon emission computed tomography in anti-IgLON5 disease: a new case mimicking probable progressive supranuclear palsy and review of the literature. Eur. J. Neurol. 28, 1392-1395. doi: 10.1111/ENE.14634

Hassan, A., Whitwell, J. L., and Josephs, K. A. (2011). The corticobasal syndromeAlzheimer's disease conundrum. Expert Rev. Neurother. 11, 1569-1578. doi: 10.1586/ERN.11.153

Hierro, D. X. M., Rojas, G., Aldinio, V., Bres-Bullrich, M., Da-Prat, G., Ebner, R., et al. (2020). Moaning phenomenon and rapidly progressive dementia in anti LGI-1 associated progressive supranuclear palsy syndrome. Tremor Other Hyperkinet. Mov. 10:8. doi: 10.5334/TOHM.65

Hofmann, J. W., Seeley, W. W., and Huang, E. J. (2019). RNA binding proteins and the pathogenesis of frontotemporal lobar degeneration. Annu. Rev. Pathol. 14, 469-495. doi: 10.1146/ANNUREV-PATHMECHDIS-012418-012955

Höglinger, G. U., Respondek, G., Stamelou, M., Kurz, C., Josephs, K. A., Lang, A. E., et al. (2017). Clinical diagnosis of progressive supranuclear palsy: the movement disorder society criteria. Mov. Disord. 32, 853-864. doi: 10.1002/mds.26987

Hong, J. Y., Yun, H. J., Sunwoo, M. K., Ham, J. H., Lee, J.-M., Sohn, Y. H., et al. (2015). Comparison of regional brain atrophy and cognitive impairment between pure akinesia with gait freezing and Richardson's syndrome. Front. Aging Neurosci. 7:180. doi: 10.3389/FNAGI.2015.00180 
Hsu, J. L., Chen, S. H., Hsiao, I. T., Lu, C. S., Yen, T. C., Okamura, N., et al. (2020). 18F-THK5351 PET imaging in patients with progressive supranuclear palsy: associations with core domains and diagnostic certainty. Sci. Rep. 10:19410. doi: 10.1038/s41598-020-76339-0

Hu, W. T., Rippon, G. W., Boeve, B. F., Knopman, D. S., Petersen, R. C., Parisi, J. E., et al. (2009). Alzheimer's disease and corticobasal degeneration presenting as corticobasal syndrome. Mov. Disord. 24, 1375-1379. doi: 10.1002/MDS.2 2574

Im, S. Y., Kim, Y. E., and Kim, Y. J. (2015). Genetics of progressive supranuclear palsy. J. Mov. Disord. 8, 122-129. doi: 10.14802/JMD.15033

Ishizuchi, K., Takizawa, T., Tezuka, T., Takahata, K., Seki, M., Tabuchi, H., et al. (2021). A case of progressive supranuclear palsy with predominant cerebellar ataxia diagnosed by [18F]PM-PBB3 tau PET. J. Neurol. Sci. 425:117440. doi: 10.1016/J.JNS.2021.117440

Jabbari, E., Holland, N., Chelban, V., Jones, P. S., Lamb, R., Rawlinson, C., et al. (2020). Diagnosis across the spectrum of progressive supranuclear palsy and corticobasal syndrome. JAMA Neurol. 77, 377-387. doi: 10.1001/jamaneurol. 2019.4347

Jang, W., Kim, J.-S., Ahn, J. Y., and Kim, H.-T. (2011). Reversible progressive supranuclear palsy-like phenotype as an initial manifestation of HIV infection. Neurol. Sci. 33, 1169-1171. doi: 10.1007/S10072-011-0875-Y

Josephs, K. A., Ishizawa, T., Tsuboi, Y., Cookson, N., and Dickson, D. W. A. (2002). Clinicopathological study of vascular progressive supranuclear palsy: a multiinfarct disorder presenting as progressive supranuclear palsy. Arch. Neurol. 59, 1597-1601. doi: 10.1001/ARCHNEUR.59.10.1597

Josephs, K. A., Katsuse, O., Beccano-Kelly, D. A., Lin, W.-L., Uitti, R. J., Fujino, Y., et al. (2006). Atypical progressive supranuclear palsy with corticospinal tract degeneration. J. Neuropathol. Exp. Neurol. 65, 396-405. doi: 10.1097/01.jnen. 0000218446.38158 .61

Kanazawa, M., Shimohata, T., Endo, K., Koike, R., Takahashi, H., and Nishizawa, M. (2012). A serial MRI study in a patient with progressive supranuclear palsy with cerebellar ataxia. Parkinsonism Relat. Disord. 18, 677-679. doi: 10.1016/J. PARKRELDIS.2011.11.011

Kanazawa, M., Shimohata, T., Toyoshima, Y., Tada, M., Kakita, A., Morita, T., et al. (2009). Cerebellar involvement in progressive supranuclear palsy: a clinicopathological study. Mov. Disord. 24, 1312-1318. doi: 10.1002/mds.22583

Kanazawa, M., Tada, M., Onodera, O., Takahashi, H., Nishizawa, M., and Shimohata, T. (2013). Early clinical features of patients with progressive supranuclear palsy with predominant cerebellar ataxia. Parkinsonism Relat. Disord. 19, 1149-1151. doi: 10.1016/J.PARKRELDIS.2013.07.019

Kannoth, S., Anandakkuttan, A., Mathai, A., Sasikumar, A. N., and Nambiar, V. (2016). Autoimmune atypical parkinsonism - a group of treatable parkinsonism. J. Neurol. Sci. 362, 40-46. doi: 10.1016/J.JNS.2016.01.006

Katisko, K., Cajanus, A., Korhonen, T., Remes, A. M., Haapasalo, A., and Solje, E. (2019). Prodromal and early bvFTD: evaluating clinical features and current biomarkers. Front. Neurosci. 13:658. doi: 10.3389/FNINS.2019.00658

King, A., Curran, O., and Al-Sarraj, S. (2013). Atypical progressive supranuclear palsy presenting as primary lateral sclerosis. J. Neurol. Sci. 329:69. doi: 10.1016/ j.jns.2013.03.015

Koga, S., Aoki, N., Uitti, R. J., Van Gerpen, J. A., Cheshire, W. P., Josephs, K. A., et al. (2015). When DLB, PD, and PSP masquerade as MSA. Neurology 85, 404-412. doi: 10.1212/WNL.0000000000001807

Koga, S., Josephs, K. A., Ogaki, K., Labbé, C., Uitti, R. J., Graff-Radford, N., et al. (2016). Cerebellar ataxia in progressive supranuclear palsy: an autopsy study of PSP-C. Mov. Disord. 31, 653-662. doi: 10.1002/mds.26499

Kovacs, G. G., Lukic, M. J., Irwin, D. J., Arzberger, T., Respondek, G., Lee, E. B., et al. (2020). Distribution patterns of tau pathology in progressive supranuclear palsy. Acta Neuropathol. 140, 99-119. doi: 10.1007/s00401-020-02158-2

Kurz, C., Ebersbach, G., Respondek, G., Giese, A., Arzberger, T., and Höglinger, G. U. (2016). An autopsy-confirmed case of progressive supranuclear palsy with predominant postural instability. Acta Neuropathol. Commun. 4:120. doi: 10.1186/s40478-016-0391-7

Lanza, G., Papotto, M., Pennisi, G., Bella, R., and Ferri, R. (2014). Epileptic seizure as a precipitating factor of vascular progressive supranuclear palsy: a case report. J. Stroke Cerebrovasc. Dis. 23, e379-e381. doi: 10.1016/J. JSTROKECEREBROVASDIS.2013.12.043

Lee, Y.-E. C., Williams, D. R., and Anderson, J. F. I. (2018). Prospective characterization of cognitive function in typical and 'brainstem predominant'progressive supranuclear palsy phenotypes. J. Mov. Disord. 11, 72-77. doi: 10.14802/jmd.17067

Levin, J., Kurz, A., Arzberger, T., Giese, A., and Höglinger, G. U. (2016). ÜBERSICHTSARBEIT: differenzialdiagnose und therapie der atypischen Parkinson-syndrome. Dtsch. Arztebl. Int. 113, 61-69. doi: 10.3238/arztebl.2016. 0061

Ling, H., de Silva, R., Massey, L. A., Courtney, R., Hondhamuni, G., Bajaj, N., et al. (2014). Characteristics of progressive supranuclear palsy presenting with corticobasal syndrome: a cortical variant. Neuropathol. Appl. Neurobiol. 40, 149-163. doi: 10.1111/nan.12037

Litvan, I., Agid, Y., Calne, D., Campbell, G., Dubois, B., Duvoisin, R. C., et al. (1996). Clinical research criteria for the diagnosis of progressive supranuclear palsy (Steele-Richardson-Olszewski syndrome): report of the NINDS-SPSP International Workshop. Neurology 47, 1-9. doi: 10.1212/WNL.47.1.1

Lope-Piedrafita, S. (2018). Diffusion tensor imaging (DTI). Methods Mol. Biol. 1718, 103-116. doi: 10.1007/978-1-4939-7531-0_7

Magherini, A., Pentore, R., Grandi, M., Leone, M. E., and Nichelli, P. F. (2007). Progressive supranuclear gaze palsy without parkinsonism: a case of neuro-Whipple. Parkinsonism Relat. Disord. 13, 449-452. doi: 10.1016/J. PARKRELDIS.2006.05.035

Meyer, P. T., Frings, L., Rücker, G., and Hellwig, S. (2017). 18F-FDG PET in Parkinsonism: differential diagnosis and evaluation of cognitive impairment. J. Nucl. Med. 58, 1888-1898. doi: 10.2967/JNUMED.116.186403

Murialdo, A., Marchese, R., Abbruzzese, G., Tabaton, M., and Michelozzi, G. S. S. (2000). Neurosyphilis presenting as progressive supranuclear palsy. Mov. Disord. 15, 730-731. doi: 10.1002/1531-8257(200007)15:4<730::aid$\mathrm{mds} 1020<3.0 . \mathrm{co} ; 2-\mathrm{o}$

Nagao, S., Yokota, O., Nanba, R., Takata, H., Haraguchi, T., Ishizu, H., et al. (2012). Progressive supranuclear palsy presenting as primary lateral sclerosis but lacking parkinsonism, gaze palsy, aphasia, or dementia. J. Neurol. Sci. 323, 147-153. doi: 10.1016/J.JNS.2012.09.005

Nakahara, K., Nakane, S., Kitajima, M., Masuda-Narita, T., Matsuo, H., and Ando, Y. (2019). Diagnostic accuracy of MRI parameters in pure akinesia with gait freezing. J. Neurol. 267, 752-759. doi: 10.1007/S00415-019-09635-Z

Ohyagi, M., Ishibashi, S., Ohkubo, T., Kobayashi, Z., Mizusawa, H., Yokota, T., et al. (2017). Subacute supranuclear palsy in anti-Hu paraneoplastic encephalitis. Can. J. Neurol. Sci. 44, 444-446. doi: 10.1017/CJN.2016.430

Owens, E., Josephs, K. A., Savica, R., Hassan, A., Klassen, B., Bower, J., et al. (2016). The clinical spectrum and natural history of pure akinesia with gait freezing. J. Neurol. 263, 2419-2423. doi: 10.1007/S00415-016-8278-X

Pan, X., and Chen, X. (2013). Clinic, neuropathology and molecular genetics of frontotemporal dementia: a mini-review. Transl. Neurodegener. 2:8. doi: 10. 1186/2047-9158-2-8

Panegyres, P. K., Edis, R., Beaman, M., and Fallon, M. (2006). Primary Whipple’s disease of the brain: characterization of the clinical syndrome and molecular diagnosis. QJM 99, 609-623. doi: 10.1093/qjmed/hcl081

Pardini, M., Huey, E. D., Spina, S., Kreisl, W. C., Morbelli, S., Wassermann, E. M., et al. (2019). FDG-PET patterns associated with underlying pathology in corticobasal syndrome. Neurology 92:e1121. doi: 10.1212/WNL. 0000000000007038

Peregrin, J., and Malikova, H. (2015). Primary Whipple disease of the brain: case report with long-term clinical and MRI follow-up. Neuropsychiatr. Dis. Treat. 11, 2461-2469. doi: 10.2147/NDT.S92066

Perini, G., Cotta Ramusino, M., Sinforiani, E., Franciotta, D., Trifirò, G., Ceroni, M., et al. (2019). Role of cerebrospinal fluid biomarkers and (18)F-florbetapir PET imaging in the diagnosis of primary progressive aphasia: a retrospective analysis. Alzheimer Dis. Assoc. Disord. 33, 282-284. doi: 10.1097/WAD. 0000000000000289

Quattrone, A., Caligiuri, M. E., Morelli, M., Nigro, S., Vescio, B., Arabia, G., et al. (2019). Imaging counterpart of postural instability and vertical ocular dysfunction in patients with PSP: a multimodal MRI study. Parkinsonism Relat. Disord. 63, 124-130. doi: 10.1016/j.parkreldis.2019.02.022

Rabadia, S. V., Litvan, I., Juncos, J., Bordelon, Y., Riley, D. E., Standaert, D., et al. (2019). Hypertension and progressive supranuclear palsy. Parkinsonism Relat. Disord. 66, 166-170. doi: 10.1016/J.PARKRELDIS.2019.07.036

Rademakers, R., Neumann, M., and Mackenzie, I. R. A. (2012). Recent advances in the molecular basis of frontotemporal dementia. Nat. Rev. Neurol. 8, 423-434. doi: 10.1038/NRNEUROL.2012.117 
Respondek, G., Stamelou, M., Kurz, C., Ferguson, L. W., Rajput, A., Chiu, W. Z., et al. (2014). The phenotypic spectrum of progressive supranuclear palsy: a retrospective multicenter study of 100 definite cases. Mov. Disord. 29, 17581766. doi: 10.1002/mds. 26054

Roh, J. H., Suh, M. K., Kim, E. J., Go, S. M., Na, D. L., and Seo, S. W. (2010). Clinical/scientific notes: glucose metabolism in progressive nonfluent aphasia with and without parkinsonism. Neurology 75, 1022-1024. doi: 10.1212/WNL. 0b013e3181f25ebb

Rohrer, J. D., Paviour, D., Bronstein, A. M., O’Sullivan, S. S., Lees, A., and Warren, J. D. (2010). Progressive supranuclear palsy syndrome presenting as progressive nonfluent aphasia: a neuropsychological and neuroimaging analysis. Mov. Disord. 25, 179-188. doi: 10.1002/mds.22946

Rösler, T. W., Tayaranian Marvian, A., Brendel, M., Nykänen, N. P., Höllerhage, M., Schwarz, S. C., et al. (2019). Four-repeat tauopathies. Prog. Neurobiol. 180:101644. doi: 10.1016/j.pneurobio.2019.101644

Sakae, N., Josephs, K. A., Litvan, I., Murray, M. E., Duara, R., Uitti, R. J., et al. (2019). Clinicopathologic subtype of Alzheimer's disease presenting as corticobasal syndrome. Alzheimers Dement. 15, 1218-1228. doi: 10.1016/J. JALZ.2019.04.011

Sanchez-Contreras, M., Heckman, M. G., Tacik, P., Diehl, N., Brown, P. H., SotoOrtolaza, A. I., et al. (2017). Study of LRRK2 variation in tauopathy: progressive supranuclear palsy and corticobasal degeneration. Mov. Disord. 32, 115-123. doi: 10.1002/MDS.26815

Schonhaut, D. R., McMillan, C. T., Spina, S., Dickerson, B. C., Siderowf, A., Devous, M. D., et al. (2017). 18F-flortaucipir tau PET distinguishes established progressive supranuclear palsy from controls and Parkinson's disease: a multicenter study. Ann. Neurol. 82, 622-634. doi: 10.1002/ANA.25060

Seeley, W. W. (2019). Behavioral variant frontotemporal dementia. Contin. Lifelong Learn. Neurol. 25, 76-100. doi: 10.1212/CON.0000000000000698

Sharma, P., Garg, R. K., Somvanshi, D. S., and Malhotra, H. S. (2011). Progressive supranuclear palsy like syndrome: neurocysticercosis an unusual cause. Neurol. India 59, 484-485. doi: 10.4103/0028-3886.82763

Shelley, B. P., Hodges, J. R., Kipps, C. M., Xuereb, J. H., and Bak, T. H. (2009). Is the pathology of corticobasal syndrome predictable in life? Mov. Disord. 24, 1593-1599. doi: 10.1002/MDS.22558

Simard, C., Vogrig, A., Joubert, B., Muñiz-Castrillo, S., Picard, G., Rogemond, V., et al. (2020). Clinical spectrum and diagnostic pitfalls of neurologic syndromes with Ri antibodies. Neurol. Neuroimmunol. Neuroinflamm. 7:e699. doi: 10. 1212/NXI.0000000000000699

Spinelli, E. G., Mandelli, M. L., Miller, Z. A., Santos-Santos, M. A., Wilson, S. M., Agosta, F., et al. (2017). Typical and atypical pathology in primary progressive aphasia variants. Ann. Neurol. 81, 430-443. doi: 10.1002/ANA.24885

Stamelou, M., Quinn, N. P., and Bhatia, K. P. (2013). “Atypical” atypical parkinsonism: new genetic conditions presenting with features of progressive supranuclear palsy, corticobasal degeneration, or multiple system atrophy-a diagnostic guide. Mov. Disord. 28, 1184-1199. doi: 10.1002/MDS.25509

Steele, J. C., Richardson, J. C., and Olszewski, J. (1964). Progressive supranuclear palsy: a heterogeneous degeneration involving the brain stem, basal ganglia and cerebellum with vertical gaze and pseudobulbar palsy, nuchal dystonia and dementia. Arch. Neurol. 10, 333-359. doi: 10.1001/archneur.1964. 00460160003001

Takkar, A., Mehta, S., Gupta, N., Bansal, S., and Lal, V. (2020). Anti- RI antibody associated progressive supranuclear palsy like presentation in a patient with breast carcinoma. J. Neuroimmunol. 347:577345. doi: 10.1016/J.JNEUROIM. 2020.577345

Tan, J. H., Goh, B. C., Tambyah, P. A., and Wilder-Smith, E. (2005). Paraneoplastic progressive supranuclear palsy syndrome in a patient with B-cell lymphoma. Parkinsonism Relat. Disord. 11, 187-191. doi: 10.1016/J.PARKRELDIS.2004.09. 003

Tobin, W. O., Lennon, V. A., Komorowski, L., Probst, C., Clardy, S. L., Aksamit, A. J., et al. (2014). DPPX potassium channel antibody: frequency, clinical accompaniments, and outcomes in 20 patients. Neurology 83, 1797-1803. doi: 10.1212/WNL.0000000000000991
Vijverberg, E. G. B., Dols, A., Krudop, W. A., Milan, M. D. C., Kerssens, C. J., Gossink, F., et al. (2017). Cerebrospinal fluid biomarker examination as a tool to discriminate behavioral variant frontotemporal dementia from primary psychiatric disorders. Alzheimers Dement. Diagn. Assess. Dis. Monit. 7, 99-106. doi: 10.1016/J.DADM.2017.01.009

Vogt, B. A. (2016). Midcingulate cortex: structure, connections, homologies, functions and diseases. J. Chem. Neuroanat. 74, 28-46. doi: 10.1016/J. JCHEMNEU.2016.01.010

Wen, Y., Zhou, Y., Jiao, B., and Shen, L. (2021). Genetics of progressive supranuclear palsy: a review. J. Parkinsons Dis. 11, 93-105. doi: 10.3233/JPD202302

Whitwell, J. L., Jack, C. R., Boeve, B. F., Parisi, J. E., Ahlskog, J. E., Drubach, D. A., et al. (2010). Imaging correlates of pathology in corticobasal syndrome. Neurology 75, 1879-1887. doi: 10.1212/WNL.0B013E3181FEB2E8

Whitwell, J. L., Stevens, C. A., Duffy, J. R., Clark, H. M., Machulda, M. M., Strand, E. A., et al. (2019). An evaluation of the progressive supranuclear palsy speech/language variant. Mov. Disord. Clin. Pract. 6, 452-461. doi: 10.1002/ mdc3.12796

Whitwell, J. L., Tosakulwong, N., Botha, H., Ali, F., Clark, H. M., Duffy, J. R., et al. (2020). Brain volume and flortaucipir analysis of progressive supranuclear palsy clinical variants. Neuroimage Clin. 25:102152. doi: 10.1016/j.nicl.2019.102152

Whitwell, J. L., Tosakulwong, N., Clark, H. M., Ali, F., Botha, H., Weigand, S. D., et al. (2021). Diffusion tensor imaging analysis in three progressive supranuclear palsy variants. J. Neurol. 268, 3409-3420. doi: 10.1007/S00415-020-10360-1

Williams, D. R., de Silva, R., Paviour, D. C., Pittman, A., Watt, H. C., Kilford, L., et al. (2005a). Characteristics of two distinct clinical phenotypes in pathologically proven progressive supranuclear palsy: Richardson's syndrome and PSP-parkinsonism. Brain 128, 1247-1258. doi: 10.1093/brain/awh488

Williams, D. R., Hadeed, A., al-Din, A. S. N., Wreikat, A.-L., and Lees, A. J. (2005b). Kufor Rakeb disease: autosomal recessive, levodopa-responsive parkinsonism with pyramidal degeneration, supranuclear gaze palsy, and dementia. Mov. Disord. 20, 1264-1271. doi: 10.1002/MDS.20511

Williams, D. R., Holton, J. L., Strand, K., Revesz, T., and Lees, A. J. (2007). Pure akinesia with gait freezing: a third clinical phenotype of progressive supranuclear palsy. Mov. Disord. 22, 2235-2241. doi: 10.1002/mds.21698

Winikates, J., and Jankovic, J. (1994). Vascular progressive supranuclear palsy. J. Neural. Transm. Suppl. 42, 189-201. doi: 10.1007/978-3-7091-6641-3_15

Zwergal, A., La Fougère, C., Lorenzl, S., Rominger, A., Xiong, G., Deutschenbaur, L., et al. (2013). Functional disturbance of the locomotor network in progressive supranuclear palsy. Neurology 80, 634-641. doi: 10.1212/WNL. 0b013e318281cc43

Zwergal, A., la Fougère, C., Lorenzl, S., Rominger, A., Xiong, G., Deutschenbaur, L., et al. (2011). Postural imbalance and falls in PSP correlate with functional pathology of the thalamus. Neurology 77, 101-109. doi: 10.1212/WNL. 0B013E318223C79D

Conflict of Interest: The authors declare that the research was conducted in the absence of any commercial or financial relationships that could be construed as a potential conflict of interest.

Publisher's Note: All claims expressed in this article are solely those of the authors and do not necessarily represent those of their affiliated organizations, or those of the publisher, the editors and the reviewers. Any product that may be evaluated in this article, or claim that may be made by its manufacturer, is not guaranteed or endorsed by the publisher.

Copyright (C) 2022 Krzosek, Madetko, Migda, Migda, Jaguś and Alster. This is an open-access article distributed under the terms of the Creative Commons Attribution License (CC BY). The use, distribution or reproduction in other forums is permitted, provided the original author(s) and the copyright owner(s) are credited and that the original publication in this journal is cited, in accordance with accepted academic practice. No use, distribution or reproduction is permitted which does not comply with these terms. 